\title{
Using an Ethos of Care to Bridge the Digital Divide: Exploring Faculty Narratives During a Global Pandemic
}

\author{
Kari Goin Kono and Sonja Taylor \\ Portland State University
}

\begin{abstract}
Prior to the COVID-19 emergency, some faculty resisted the move to digital learning formats due to concerns for student equity or that engagement would suffer. The purpose of this study was to understand how faculty adapted their courses during the rapid shift to remote and online learning in the spring of 2020, and to understand the role of equity in their experiences. Faculty narratives revealed that elements such as flexibility, reducing coursework to essential content, and personalization - all stemming from an ethos of care - were effective in mitigating the equity issues that surfaced during the emergency transition to universal remote learning. Our findings support the critical importance of extending culturally sustainable practices to all online learning environments in higher education as a way to mitigate equity issues related to the digital divide. These findings are in line with, and contribute to, the growing body of research on culturally sustaining pedagogy within the context of online learning.
\end{abstract}

Keywords: culturally sustaining pedagogy, digital divide, ethos of care, narrative inquiry, online learning

Goin Kono, K. \& Taylor, S. (2021). Using an ethos of care to bridge the digital divide: Exploring faculty narratives during a global pandemic. Online Learning, 25(1), 151-165. https://doi.org/10.24059/olj.v25i1.2484

\section{Author Note}

We purposefully use the lowercase " $w$ " in the use of describing people who are white. Our intention is to decenter white privilege and acknowledge historic and ongoing inequities related to race. 


\section{Using an Ethos of Care to Bridge the Digital Divide: Exploring Faculty Narratives During a Global Pandemic}

Faculty are key contributors to student success in online learning environments. Specifically, research shows that teacher presence can radically affect student persistence and engagement (Garrison et al., 2000; Jaggars \& Xu, 2016; Markova et al., 2017; Salvo et al., 2019). Faculty presence in the online classroom is especially key for students of color and first-generation students, who succeed when they have personalized feedback from instructors, feel engaged and connected to their peers, and feel connected to course materials and topics (Salvo et al., 2019). Recognizing this fact, some faculty have resisted the move to online learning due to concerns that student equity or engagement will suffer (Wingo et al., 2017), or that they cannot afford the time required to design and teach an online course that sustains equity and engagement (Bunk et al., 2015). However, with the rapid transition to remote learning during spring of 2020, even faculty who were reluctant to teach online found themselves in a digital learning environment.

In this paper we explore faculty narratives from a large public urban university with the goal of identifying and deepening equitable practices within online learning and teaching. Culturally sustaining pedagogy (CSP), a practice centered on care, is one approach to learning that encourages the practice of sustaining student's varied ways of knowing, knowledge, and meaning making (Paris, 2012; Paris \& Alim, 2017), yet almost no articles address culturally sustaining pedagogy within online learning environments in higher education. We were specifically interested in how inequities rooted in the digital divide affected teacher practice and pedagogy during the COVID-19 crisis, and how this research might contribute to the gap in culturally sustaining pedagogy in online teaching. We provide an overview of the literature, discuss our methodology, describe our participants, and illustrate our data analysis process. We then address validity concerns and share findings supported by faculty quotes, and end with a discussion and recommendations for future research.

\section{Review of Relevant Literature}

Our review of the literature focuses on online inequities that are rooted in two sources: the digital divide, and deficit approaches to learning and teaching. We then discuss the concept of culturally sustaining pedagogy and how its practice can potentially buffer students traditionally underinvested in by academia against inequitable outcomes.

Initial research on the digital divide focused mainly on access to technology (Baym, 2015; Bennett \& Maton, 2010). As internet access became more prolific, scholarship began to focus on two distinct levels of digital divide where level 1 relates primarily to access and level 2 on proficiency of use (Bennett \& Maton, 2010; Pearce \& Rice, 2013; Tsetsi \& Rains, 2017). This dichotomous approach to understanding the digital divide has given way over time to increasingly complicated nuances related to both access and use (Gonzales et al., 2020; Tsetsi \& Rains, 2017). For example, some scholars point to four levels of divide involving "technical or theoretical access, perceived or effective access, basic use, and meaningful engagement in activities" (Pearce \& Rice, 2013, p. 723). The more complicated framing of the digital divide is associated with not just access and proficiency, but also the types of devices and kinds of activities engaged in - which are all compounded by cultural and social contexts (Bennett \& Maton, 2010; Pearce \& Rice, 2013; Tsetsi $\&$ Rains, 2017). It is also important to note the types of devices people have access to, is, by a large extent, dictated by sociodemographic factors (Gonzales et al., 2020; Pearce \& Rice, 2013). 
Deficit approaches to learning and teaching frame the cultural ways of being for many firstgeneration students and communities of color as deficiencies that must be overcome. This discourse can often label students as "problem students" who don't follow rules and lack discipline, suggesting they are lazy or unmotivated (Kaupp, 2012; McKay \& Devlin, 2015; Valenzuela, 2005). As a result, these approaches require students to assimilate to dominant language and practices in order to succeed in a white-centered, normative educational experience (Paris, 2012). Overall, this contributes to a deficit line of thinking that can be devastating for students, ultimately affecting persistence, retention, graduation rates, and overall student success (Kaupp, 2012; Yeboah \& Smith, 2016).

Culturally sustaining pedagogy (CSP) builds on decades of educational research in multicultural education (Banks, 1993; Nieto, 1992), culturally relevant pedagogy (LadsonBillings, 1995), and culturally responsive teaching (Gay, 2002). In an effort towards a loving critique, Paris (2012) calls for a move towards pedagogy that not only incorporates multicultural elements, is relevant and responsive to student's cultural identity, but also affirms and sustains the heritage of students and their communities. This includes the cultural, linguistic, and community practices of students, practice that is centered on care and awareness of the complexities and challenges that students from different backgrounds face (Heitner \& Jennings, 2016; Paris \& Alim, 2017; Robinson et. al., 2017). CSP then requires educators to respond to any current and pressing student needs with an understanding of the pressures and commitments students face and the needs students may be facing within their communities. We note the need to respond to students lives in constant states of stress, anxiety, and crisis is especially potent as students in the spring of 2020 experienced the threat of deportation, eviction, job loss, financial instability, food and housing insecurity, differences in access related to the digital divide, and the impact associated with the continuation of various racial inequities.

Research on culturally sustaining pedagogy in online learning has largely been focused on the K-12 system, demonstrating a clear gap in needed research that focuses on CSP within online learning and higher education (Heitner \& Jennings, 2016). More research is needed in this area because online learning spaces create a situation where "time, distance, technology, and connectivity inadequacies affect students" (Robinson et. al., 2017, p. 39).

In the context of an emergency shift to remote learning, it was unclear how the digital divide would impact the learning experience for teachers and students, because the nuanced variations within the digital divide are multifactorial. These nuances may be compounded within an open-access institution that serves a student body with high numbers of first-generation and historically underserved students, such as the university which serves as the context for this study. The majority of students in this university come from backgrounds which suggest the potential for struggle with the digital divide, and many of the university's faculty had little to no experience teaching in a fully remote environment. To understand how faculty adapted and the role of equity and the digital divide, our research explored the following questions:

- How have faculty adapted their practices during the shift to remote learning?

- What role did pedagogy play in course planning and execution?

- How did the digital divide shape faculty experiences (specifically equity)? 


\section{Methods}

We employ a narrative inquiry methodology to gather stories as data from faculty at a large, public urban university to understand how faculty negotiate rapid adoption and transformation into remote and digital learning contexts. The key to narrative inquiry is "the use of stories as data, and more specifically, first-person accounts of experience" (Merriam \& Tisdell, 2016, p. 34). The root of all research is founded in the process of narrative inquiry and such inquiry begins with doubt (Hendry, 2009). Narratives are where we make meaning from our experiences (Coulter et al., 2007; Hendry 2009; Taylor, 2013). More recently narrative inquiry has been used as a research method in understanding how teachers experience failure (Jungic et. al., 2020; Puzio et al., 2017) and whether or not technology "flattens" authenticity (Conlon et al., 2020). These uses of narrative inquiry make the method exceptionally relevant to our own study, where faculty are facing so much uncertainty that necessitates trial and error, within digital teaching platforms.

\section{Participants and Setting}

The study took place at a large public urban university serving over 25,000 students in the Pacific Northwest of the United States and that teaches on a quarterly system. The student body is largely nontraditional or older than 25; many students are parents with children, and many work while going to school. The study body is $52 \%$ white, a majority $(72 \%)$ of students commute to campus via transit, walking or biking, and $37 \%$ of students self-identify as first generation.

Faculty opted into our study by responding to a survey of interest and then were contacted for individual interviews. We chose individual, in-depth semi-structured interviews with faculty in order to provide them a confidential space to debrief about their experiences. Faculty were interviewed by both authors in English over Zoom for 30 to 90 minutes. Requirements for participation were to have taught during spring term, as well as have had previous experience teaching at our institution prior to the 2020 term. Twenty-six faculty responded and all 26 were offered an interview. Scheduling and time constraints were limitations for interviewing six faculty, thus 20 faculty were interviewed for this study. One interview was removed from analysis because although they met the initial criteria for an interview, their experience as discussed in the interview was solely within university administration and not teaching, resulting in a total of 19 interviewees.

Participating faculty included adjuncts, fixed-term, and tenured professors, working across all areas of the university and with various levels of seniority. For example, one faculty member had just completed their first-year teaching, and another is tenured and has been teaching for more than 25 years. Several faculty had prior online teaching experience, while others had no experience teaching online prior to the spring 2020 term.

The most significant limitation for data collection was the truncated timeframe that did not allow us to seek a broader pool of faculty coupled with the ongoing pandemic. Additionally, because faculty opted into this study, we were limited in that we only spoke with faculty who elected to talk about their experience. Further, the pandemic has been exacerbated by the eruption of national protests for racial justice and the onslaught of a historically severe fire season in the western region of our nation. These limitations make our research even more critical since remote learning will be a significant mechanism for attending classes for the foreseeable future.

\section{Data Analysis}

Interviews were audio recorded and transcribed; to protect respondent identity and confidentiality, transcripts were labeled with a pseudonym for each faculty member. We employed 
member checking, sharing transcripts with faculty to confirm their narratives along with a followup survey, which offered them a chance to include any additional information that they wanted to share. Through a grounded theory coding approach, we began with open coding interview transcripts line by line (Charmaz, 2006). We then began a focused coding approach using axial coding or the relating of concepts to each other in order to find connecting strategies (Blair, 2015; Corbin \& Strauss, 2008; Maxwell, 2013). We collected codes from the qualitative analysis software Atlas.ti, which allows for the comparison of singular codes and groups of codes in a code manager. We created a coding connection matrix to map our codes in connection across interviews. This extensive matrix (over 30 pages) allowed us to find connecting strategies between codes, to sort through the transcripts to find supporting and challenging evidence for our categories and enabled us to cross reference quotes. Coding from Atlas.ti and matrices were combined with narrative summaries to achieve an understanding of the interviews that neither could provide alone (Maxwell, 2013).

\section{Validity \& Reliability}

We acknowledged how researchers react within interviews does at times present a power dynamic over those being interviewed and that the goal of minimizing influence is not always a feasible goal of qualitative research (Maxwell, 2013). To address the influence and possible power dynamics within the interview process, we focused on several methods for addressing validity and reliability within our analysis and findings. We employed member checking with each participant where each faculty member had the opportunity to review their transcripts, confirm language, and offer feedback to the researchers. Additionally, any published quotes were confirmed by faculty. Member checking is a highly valued practice of "ruling out the possibility of misinterpreting the meaning of what participants say and do" as well as a critical way to identify research bias and potential misunderstandings from interviews (Maxwell, 2013, p. 126).

We created two matrices in how we employed our comparison strategies among faculty quotes, a validity matrix and a coding connection matrix (Maxwell, 2013). The validity matrix was developed in an effort to focus on validity and reliability within the study. Second, in an effort to further display our connecting strategies from a somewhat large participant pool, we created a coding connection matrix, which allowed us to select quotes that were representative and illustrative of each larger theme. It is important to note that to address reliability, or how results might be replicated, would be challenging, as this study was conducted in response to a global pandemic that required a universal shift of practice. As such, this study is unique and may not be able to be exactly replicated. In an effort to address and bolster reliability, we connect our findings to relevant literature that investigates equity, the digital divide, and engagement in online learning in the discussion section of this paper.

\section{Results}

Through our qualitative thematic analysis, several aspects of the digital divide were identified as barriers that faculty needed to manage: access to technology, problems with connectivity, and proficiency with technology. Additionally, faculty expressed concern that community building would not be effective in an online environment. In response to each of these possible barriers, faculty drew on the context of the pandemic to provide a mandate for placing the care of student well-being as the top priority for spring term, in what we are calling an ethos of 
care. Faculty narratives demonstrated that an ethos of care can mitigate existing challenges and strengthen student engagement.

Below, we focus on two themes that emerged in our findings that showcase this relationship. Our first theme revolves around exploring the varied and nuanced aspects of the digital divide, and our second theme demonstrates how care impacted both the student and faculty experience. We argue that these two themes taken together provide evidence that an ethos of care in response to the pandemic offered students elements of a culturally sustaining practice. Further, we suggest that continuing these practices, even in the absence of a global pandemic, will further our long-term goals for equity and inclusion in higher education.

Varied and nuanced aspects of the digital divide. Shifting to an entirely remote system of teaching in the time span of one week brought concerns from faculty who worried about relying solely on technology and whether or not students would succeed during spring term. Faculty who had never taught online were fully immersed in the practice, almost overnight. Those with experience teaching online became resident experts, trying to help their colleagues get through, while encountering their own challenges. While faculty in our study who had experience teaching online felt well prepared pedagogically, not all could anticipate the increased barriers to engagement and access that arose during spring term. The most prominent barriers described by faculty were both technical and emotional: an inability to bear witness, a lack of confidence in ability to use technology for teaching, and issues of connectivity. We describe each of these three barriers in more detail below.

First, in terms of inability to bear witness, faculty described having difficulty with not having immediate access to students' reactions. For example, Aria, a faculty new to teaching online struggled with not being able to witness the learning moments happen for her students.

One thing I really don't like about teaching asynchronously is I don't get to see any of it happening. So, they tell me they learn a lot. But you don't get any of the reward of seeing that light bulb moment...I think it was more successful in the virtual format for them, but I didn't get to see any of it. -Aria

Although several faculty worried about being able to witness student learning, Henry, a seasoned online faculty member told us, "what I keep trying to tell my colleagues is, just because you're not witnessing your students having a powerful pedagogical experience, doesn't mean they're not having one. The feedback loop for online teaching is slower or longer."

Second, in terms of lack of confidence, faculty who had experience teaching online reflected that they had initially felt confident in their ability to successfully shift to remote learning, but some nevertheless encountered unexpected barriers to equity. Some of these challenges related to the location of their students. For example, some international students were evacuated and had to work around different time zones in order to get to class. One faculty member shared that she had students who were moving every month because they were unable to make rent. These students did not necessarily have a reliable connection to the internet, nor did they always have a safe space from which to join their class. Some faculty expressed frustration with the limitations of a digital framework and this seemed to come from a combination of lack of experience in delivering online learning and a belief that the digital environment was not conducive to their pedagogical approach.

I had never done a zoom class before. I've never done an online class. I actually believe that the in-person experience is a fundamental orientation principle. A fundamental 
principle of teaching is to be able to connect in real time with other human beings, whether it's me speaking in front of a group of students or allowing the students to get into smaller groups and interact with each other. -Gabriel

Technology is great, but at the same time, expectedly issues occur. [One] morning, my internet shut down, so I had to think of a solution. Luckily, I [could] use my [cellular] data to do the Zoom class, but without the camera so that I could save the data. I told my students 'I will only use the audio until my Internet comes back.' So, we survived like that. -Luna

Third, in terms of connectivity, nearly all interviewees mentioned that how students interacted with and modified technology may have had an impact on community building in relation to student-teacher interaction. Specifically, one thing that continued to be a challenge was when students elected to turn their microphone and camera off and faculty were presented with a blank screen.

New students that I've never met in person before, the only information I have is like this weird little head and shoulder rectangle. There are a number of people with technology, challenges in different ways. And so they would leave their camera off the entire time. And so it's camera off, with a muted microphone. So it's just this very anonymous square with, you know, some initials there, which feels like a barrier to establishing a relationship or trust. -Grace.

I think silence is more challenging with zoom. Silence is challenging. But you can create that space where people trust each other to be in silence to be feeling the things they're feeling. I think that's very potent for students. With the zooming, silence is challenging in a different way because, well one I can't see everyone. So as a facilitator of this silence, I'm not... I want to make sure it's an inclusive silence. It's not like silence out of fear or a silence out of what we are supposed to be doing. And that's very challenging with not being able to at least see everybody. -Gabriel

Although Grace and Gabriel note the difficulties that came from their emergency shift to remote learning, many faculty found ways to successfully build community despite technological challenges. In navigating the difficulties that came with relying completely on remote teaching to reach learning outcomes, faculty leaned on their ability to be flexible in adapting to the individual needs of students.

The great majority of my students are first generation and the vast majority of them live at home. The vast majority of them are from modest to low-income families. So flexibility is really important. I was pleasantly surprised that just about everyone who wanted to do zoom could. But there were some for whom technology was a challenge, you know? So I guess that was the main adjustment I needed to make to make sure there were a variety of ways that people could meet the requirements. -Caleb

All of my students were not [local]. Lots of them went back to wherever, or had trouble getting back .. So I switched [the assignment] to doing neighborhood projects about where they lived. -Isla.

Both the student and faculty experience in the spring of 2020 were impacted by access to technology, access to internet and bandwidth, and having to adjust to new home life that presented various disruptions and inequities. Many faculty had to balance home lives with children and other complications while students' lives were affected by evictions, travel complications, job loss, food 
insecurity, and the threat of deportation. Although we have centered quotes as evidentiary support from Caleb and Isla, faculty shared many stories about adapting to meet the community needs of each student. In adapting to meet these needs, faculty in our study chose to center care for their students as a means of addressing the many difficulties created by the emergency shift to remote learning.

The impact of care. While the barriers stemming from the shift to remote learning did cause some frustration, many faculty were able to overcome these challenges through more oneto-one interactions with students, flexibility around attendance, and a combination of asynchronous and synchronous teaching strategies. Among faculty who experienced strong student engagement and connection, two themes were apparent: Growing as a professional, and offering flexibility and simplification to students.

In terms of growing as a professional, all faculty were challenged by a continually changing landscape during spring term that required multiple shifts in assignments and approaches. In some cases, faculty operated strictly in survival mode, but in other cases faculty were surprised to discover inner reservoirs of compassion or patience and found that the experience of remote teaching provided a powerful and lasting impact on their practice moving forward.

What we went through in the spring, was triage, it was damage control. We never knew what was going to happen each week. So, we should forgive ourselves and be more open minded and more compassionate for one another and give online learning another chance. There are so many advantages to online instruction. Sure, there were problems in the spring, nevertheless this was a huge lifeboat for so many of us. -Henry

I'm not going to be the best at it and that the students are not going to be the best at it. So my most important consideration was that I have to be patient with myself and patient with them. - Elijah

Henry and Elijah share a sense of urgency and awareness described by many of the faculty we spoke with about the shift to remote learning. Both faculty participants also acknowledge that there would be mistakes and that patience would be required from both students and faculty. However, within the space of patience and forgiveness, several faculty acknowledged the opportunity to grow as a professional and gain a new appreciation for what remote learning and digital spaces could provide them.

Hazel says, "The pivot to teaching remotely was a bit of baptism by fire for me - but in a good way. I was stretched as an educator, because I would not have willingly taught this way before the pandemic required it of me." In some cases, however, it is important to note that faculty didn't simply push through it; some faculty genuinely found themselves thriving in ways that surprised them. Faculty describe how they encountered opportunities and valuable shifts in perspective that brought a depth and sense of gratitude to their remote teaching experience:

It's kind of an extraordinary adventure. I mean, I know that obviously there were terrible consequences for many people. And, it's not like this is over in any way, shape or form. People are struggling, they've lost jobs, they've lost livelihoods. People have lost lives and people lost people that they care about. So I don't mean to not acknowledge how horrible a lot of this is. But it's another example of a pretty significant challenge affecting our communities... There are creative, effective ways to reconnect and make us stronger and 
reveal to us that we have a lot of reserve and ability and potential. This is not the last time something like this will happen. - Owen

Probably one of the most meaningful terms I've ever had, in nine years of teaching. I don't even know how to encapsulate it except to say that I had to grow so much in the moment and... you go into it in the beginning of the term with this idea of what has to happen and just the grace my students extended to me, and to each other. It was really powerful. I think at the end of the day, I had much, much more connection, the class was more connected, and I got better work out of the students. I got better attendance, I got better participation. Our discussions were deeper and more thoughtful and more focused. It was pretty powerful, actually. -Olivia

In general, some faculty described their experience as simply surviving, while others found opportunities to thrive and to support their students in doing so.

Faculty who responded with a culture of care seemed to pursue two interrelated strategies: simplifying their curriculum and supporting student needs with higher-than-normal flexibility to meet course goals. The combination of these key concepts allowed faculty to develop resiliency during their emergency shift to remote learning and resulted in higher perceived levels of student engagement.

I set out to create a class that was adaptable. Some of it was adaptable in the middle of the term. I said to my students, "I think we need to switch gears now." I paired my class back, I took out some of the assignments that I would normally do in a face-to-face class and really streamlined. And tried to make it even more reflective than my class already is. What I discovered, which I found really, really intriguing was that they really craved that community and they would show up even if they didn't have to. -Olivia

So gradually, gradually I simplified for their sake, my sake. And, actually, they learned better. This did not compromise their learning experience by any means. Because what I saw in week eight and nine was that the clarity and the high level of accuracy, they reached in such a little time... in face to face, they would have never reached it. -Himari

In describing the ways they simplified their courses, faculty shared how they narrowed in on the learning outcomes and made sure assignments addressed those outcomes. In addition, many faculty pared down the amount of work to get to what was essential to reach class outcomes. In some cases, faculty worked with students to come up with ways to meet the learning outcomes if students fell behind in their coursework and in some cases students overperformed. Faculty in our study were surprised to find that their students engaged more and demonstrated deeper learning when offered flexibility around deadlines and when content was simplified as a response to the pandemic. This became particularly apparent when it came to class discussions. Faculty explained that not only were class discussions richer and deeper, but more of the students were engagingstudents who were previously silent in face-to-face classes showed up and expressed themselves in the online discussion boards.

Students were just doing fantastic discussion posts, using the prompt I had provided them. From reading those I truly feel like [students] had a better grasp of the course material than they would have if they were just showing up in class. -Henry 
I've had a lot of my [students of color] say to me that they felt like in the remote zoom format, they felt more comfortable initiating discussions, participating in discussions in a way that they would never feel in a classroom. So I found that to be really interesting. -Olivia

Although both Henry and Olivia spoke to the rich discussions and deep connections that they felt with students, one aspect of care that was challenging for faculty was the extra time and emotional labor involved in trying to meet the various needs for all their students. In addition, not all faculty experienced deeper engagement with their students. Some faculty expressed frustration when it came to maintaining attention in light of the ongoing health crisis. For example, Isla noted, "I felt like I spent so many hours on this course, and it was really hard to set boundaries."

One of the main concerns faculty voiced going into spring term was that they would not be able to make connections with students. Despite these concerns, several faculty were surprised to have made stronger connections with students compared to their experience in face-to-face classes. Further, even faculty who were the most skeptical about remote learning and who had the most difficulty adapting, still experienced the type of connection they were hoping for at least once.

When we're all remote, it allows that space to I don't know, I just think even though I maybe spend more time, I feel like it's more quality time. And at the end of the day, it's more focused time. It's not this crazy commuting and running around and having a, you know, three unproductive hours in between or six hours between two classes or whatever, you know. And I think for students too, it allows them more access to us. -Olivia

In sum, through a series of narrative inquiry interviews and a qualitative thematic analysis, faculty used an ethos of care to bridge several barriers presented from the digital divide in order to specifically address equity and access. As part of that ethos of care, faculty acknowledged their own limitations and embraced the challenges in a very real way. As Himari stated emphatically, "perfection is not the solution" and as Olivia poignantly shares, "the more real we are, the more we give them permission to breathe." Additionally, faculty narrated that with heightened levels of flexibility, simplification, and care, they experienced higher levels of student engagement. Several faculty were even able to offer a more centered and personalized learning experience for students with more feedback and one-to-one connections than time would permit in a face-to-face setting.

\section{Discussion}

This study demonstrated the resiliency and challenges faculty at one large public urban university experienced as they adapted to fully remote learning, under the traumatic circumstances of a global pandemic. Although experiences amongst faculty differed in the spring of 2020, all who participated in our study were able to adapt - some with extremely meaningful and positive outcomes and some with a sense of surviving the inevitable. Faculty reported problems with technology, including unstable connections, issues with devices, and a learning curve in relation to different technology. The various challenges faculty described reflect the nuanced nature of the digital divide articulated in current research (Gonzales et al., 2020; Tsetsi \& Rains, 2017). Our results reflect that reticence and reluctance toward online learning persisted, as many faculty in our study felt challenged and skeptical that they would be able to build community and trust with students remotely. In particular some faculty struggled with the anonymity provided by digital learning platforms and the time necessary for developing deeper levels of connection necessitated 
by the online context. However, even faculty with the most reluctance in our study related at least one experience with authentic and moving connection, suggesting that the possibilities for building engagement remotely are more expansive that previous research has shown.

Importantly, when faculty employed pedagogy that honored the student experience, namely flexibility, simplification, and care, many witnessed higher levels of student engagement. Additionally, we found that faculty were able to offer a more centered and personalized learning experience for students through feedback and one-to-one connections. Our results are particularly significant because one rationale faculty offer for resisting online teaching stems from a fear that student engagement suffers in the context of online learning (Wingo et al., 2017).

An important finding to consider is that during a time of crisis, faculty employed practices that responded to the needs of students and their communities and as a result, we argue, were culturally sustaining. Although faculty were surprised when pedagogy that responded to students' needs seemed to increase engagement, many faculty members indicated they would continue with these practices in their classrooms moving forward. This data may indicate that the rapid transition to remote and online learning increased opportunities for faculty to practice culturally sustaining pedagogy. We do want, however, to acknowledge that there is a blurry link between "between sustaining survival and sustaining liberation" (Wong \& Peña, 2017, p. 119). During heightened times of stress, such as during a global pandemic, the most important pedagogy educators can bring is an ethos of care and flexibility to meet the various needs of their students.

We argue that in the time of COVID, faculty who responded to the needs of their students by sustaining the student's survival in the class did offer liberatory practices as shown through the demonstrative narratives on increased engagement. However, it is important to note this response was not necessarily an intentional effort to culturally include and honor students' lived experiences and cultural connection to their communities but was prompted as a necessity in response to a time of crisis. As times change, so will the community needs of our students. When we consider care as an element of culturally sustaining pedagogy, we argue that liberation through culturally sustaining pedagogy requires faculty to foster higher levels of self-determination and democratization in the online classroom in order to achieve social justice. Liberatory practices geared towards action are key to student success and the deconstruction of inequities that have plagued generations of communities of color for centuries. Faculty striving for equitable practices in online classrooms need to focus on intentional efforts to center student's cultures and community needs and not only in response to a time of crisis.

We call on faculty to hold onto teaching practices that respond to the various needs of their students and to build on that by bringing in more of a social justice focus - namely culturally sustaining pedagogy that honors students cultural and linguistic connections to their communities. Culturally sustaining pedagogy is not only a set of practices, it is a fundamental reimagining of the purpose of education as a system that is critical, emancipatory, and one that reframes the role of the student and the role of the faculty member to respond to the needs of their communities, which was certainly exhibited during the spring of 2020 (Paris \& Alim, 2017).

Employing pedagogy that responded to the cultural and community needs of students during a global pandemic demonstrated that faculty who adapt with flexibility, simplification, and care, reduced barriers to learning for many students. If faculty had not had to make these adjustments, they might not have discovered the ways that online learning could facilitate a more 
personalized student experience, which demonstrated a level of growth and transition within their teaching practice, ultimately leading to higher levels of student engagement.

\section{Suggestions for future research}

Our research contributes to the literature in several important ways. First, we show that despite faculty concerns about online learning and student engagement, building authentic community online is possible in multiple ways. Second, in bringing their pedagogy of care online, some faculty in our study were able to see deeper engagement and students met course learning outcomes faster than expected. Finally, we inch closer to research that addresses culturally sustaining pedagogy in online higher education. Future research will engage further with culturally sustaining pedagogy in online learning, focusing on action and liberation so we can potentially address the ongoing social issues we continue to grapple with in higher education.

We recognize that we have an incomplete picture because we focused on the faculty experience and we acknowledge the importance of our students' voice in providing a deeper understanding of how learning shifted as a result of the global pandemic. Research on the student experience is likely in progress at this time and we argue that students should be thought of as partners in future research. 


\section{References}

Adams, M., Rodriguez, A., \& Zimmer, K. (2018). Studying cultural relevance in online courses: A thematic inquiry. Online Learning, 22(4), 361-381.

Banks, J., A. (1993). Chapter 1: Multicultural education: Historical development, dimensions, and practice. Review of Research in Education, 19(1), 3-49.

Baym, N. K. (2015). Personal connections in the digital age. John Wiley \& Sons.

Bennett, S., \& Maton, K. (2010). Beyond the "digital natives" debate: Towards a more nuanced understanding of students' technology experiences. Journal of Computer Assisted Learning, 26(5), 321-331.

Blundell, R., Costa Dias, M., Joyce, R., \& Xu, X. (2020). COVID-19 and inequalities. Fiscal Studies, 41(2), 291-319.

Blackburn, M. V. (2014). Humanizing research with LGBTQ youth through dialogic communication, consciousness raising, and action. In D. Paris \& M. T. Winn (Eds.), Humanizing Research: Decolonizing qualitative inquiry with youth and communities (pp. 43-57). Sage Publications.

Blair, E. (2015). A reflexive exploration of two qualitative data coding techniques. Journal of Methods and Measurement in the Social Sciences, 6(1), 14-29.

Buelow, J. R., Barry, T., \& Rich, L.E. (2018). Supporting learning engagement with online students. Online Learning, 22(4), 313-340.

Bunk, J., Li, R., Smidt, E., Bidetti, C., \& Malize, B. (2015). Understanding faculty attitudes about distance education: The importance of excitement and fear. Online Learning, 19(4), $1-11$.

Charmaz, K. (2006). Constructing grounded theory: A practical guide through qualitative analysis. Sage Publications.

Conlon, M. M., Smart, F., \& McIntosh, G. (2020). Does technology flatten authenticity? Exploring the use of digital storytelling as a learning tool in mental health nurse education. Technology, Pedagogy and Education, 3(1), 1-10.

Corbin, J., \& Strauss, A. (2008). Basics of qualitative research: Techniques and procedures for developing grounded theory (3rd ed.). Sage Publications.

Coulter, C., Michael, C., \& Poynor, L. (2007). Storytelling as pedagogy: An unexpected outcome of narrative inquiry. Curriculum Inquiry, 37(2), 103-122.

Garrison, D. \& Anderson, T., \& Archer, W. (2000). Critical inquiry in a text-based environment: Computer conferencing in higher education. The Internet and Higher Education, 2(2-3), $87-105$.

Gay, G. (2002). Preparing for culturally responsive teaching. Journal of Teacher Education, 53(2), 106-116.

Gonzales, A. L., Calarco, J. M., \& Lynch, T. (2020). Technology problems and student achievement gaps: A validation and extension of the technology maintenance construct. Communication Research, 47(5), 750-770. 
Heitner, K. L., \& Jennings, M. (2016). Culturally responsive teaching knowledge and practices of online faculty. Online Learning, 20(4), 54-78.

Hendry, P. M. (2009). Narrative as inquiry. The Journal of Educational Research, 103(2), 7280.

Jaggars, S. S., \& Xu, D. (2016). How do online course design features influence student performance? Computers \& Education, 95(1), 270-284.

Jungic, V., Creelman, D., Bigelow, A., Côté, E., Harris, S., Joordens, S., Ostafichuk, P., Riddell, J., Toulouse, P., \& Yoon, J. S. (2020). Experiencing failure in the classroom and across the university. International Journal for Academic Development, 25(1), 31-42.

Kaupp, R. (2012). Online penalty: The impact of online instruction on the Latino-White achievement gap. Journal of Applied Research in the Community College, 19(2), 8-16.

Ladson-Billings, G. (1995). Toward a theory of culturally relevant pedagogy. American Educational Research Journal, 32(3), 465-491.

Ma, J., Han, X., Yang, J., \& Cheng, J. (2015). Examining the necessary condition for engagement in an online learning environment based on learning analytics approach: The role of the instructor. Internet and Higher Education, 24(1), 26-34.

Markova, T., Glazkova, I., \& Zaborova, E. (2017). Quality issues of online distance learning. Procedia-Social and Behavioral Sciences, 237(1), 685-691.

Maxwell, J. A. (2013). Qualitative research design: An interactive approach. Sage Publications.

McKay, J., \& Devlin, M. (2015). Low income doesn't mean stupid and destined for failure: challenging the deficit discourse around students from low SES backgrounds in higher education. International Journal of Inclusive Education, 20(4), 347-363.

Merriam, S. B., \& Tisdell, E. J. (2016). Qualitative research: A guide to design and implementation (4th ed.). Jossey-Bass.

Nieto, S. (1992). Affirming diversity: The sociopolitical context of multicultural education. Longman.

Paris, D. (2012). Culturally sustaining pedagogy: A needed change in stance, terminology, and practice. Educational Researcher, 41(3), 93-97.

Paris, D., \& Alim, H. S. (Eds.). (2017). Culturally sustaining pedagogies: Teaching and learning for justice in a changing world. Teachers College Press.

Pearce, K. E., \& Rice, R. E. (2013). Digital divides from access to activities: Comparing mobile and personal computer Internet users. Journal of Communication, 63(4), 721-744.

Puzio, K., Newcomer, S., Pratt, K., McNeely, K., Jacobs, M., \& Hooker, S. (2005). Creative failures in culturally sustaining pedagogy. Language Arts, 94(4), 223-233.

Robinson, H. A., Kilgore, W., \& Warren, S. J. (2017). Care, communication, learner support: Designing meaningful online collaborative learning. Online Learning, 21(4), 29-51.

Salvo, S. G., Shelton, K., \& Welch, B. (2019). African American males learning online: Promoting academic achievement in higher education. Online Learning, 23(1), 22-36. 
Taylor, J. L. (2013). The power of resilience: A theoretical model to empower, encourage and retain teachers. Qualitative Report, 18(35), 1-25.

Tsetsi, E., \& Rains, S. A. (2017). Smartphone Internet access and use: Extending the digital divide and usage gap. Mobile Media \& Communication, 5(3), 239-255.

Valenzuela, A. (2005). Subtractive schooling, caring relations, and social capital in the schooling of U.S. Mexican youth. In D. J. Flinders and S. J. Thornton (Eds.), Curriculum Studies Reader (pp. 267-278). Routledge.

Wingo, N. P., Ivankova, N. V., \& Moss, J. A. (2017). Faculty perceptions about teaching online: Exploring the literature using the technology acceptance model as an organizing framework. Online Learning 21(1), 15-35.

Wong, C., \& Peña, C. (2017). Policing and performing culture: Rethinking "culture" and the role of the arts in culturally sustaining pedagogies. In D. Paris \& H. S. Alim (Eds.), Culturally Sustaining Pedagogies: Teaching and Learning for Justice in a Changing World. (pp. 116-138). Teachers College Press.

Yeboah, A. K., \& Smith, P. (2016). Relationships between minority students online learning experiences and academic performance. Online Learning, 20(4), 1-26. 